\title{
Solución de conflictos en Comunidades nativas*
}

Johan Otoya Calle**

"La antropología no siempre se ha mostrado tan indiferente como ahora a la justicia salvaje y a sus métodos de administración".

Bronislaw Malinowski. Crimen y Costumbre en la Sociedad Salvaje, p. 15 .

\section{Introducción}

El presente trabajo tiene como punto de partida y fuente para el análisis, al «Reglamento de Administración de Justicia de Comunidades Nativas del Alto Marañón" y el trabajo de campo realizado en la Comunidad nativa Asháninka de San Miguel de Marankiari, en la Provincia de Chanchamayo. Con la ayuda del documento y de nuestra experiencia en dicha comunidad, iniciaremos nuestro estudio sobre la solución de conflictos en las Comunidades nativas.

La fuente de nuestro trabajo (el Reglamento), tiene como origen la costumbre de las diversas Comunidades Aguarunas. Dicho Reglamento, es un intento por ordenar o sistematizar el sistema de solución de conflicto de estas comunidades, intento dirigido por el Centro de Investigación y Promoción Amazónica - CIPA.

En razón de nuestras fuentes, buscaremos analizar cómo en el ordenamiento jurídico del Estado se articula o choca con la función constitucio-

* Esta investigación mereció una mención honrosa en el «V Premio Anual de Investigación PUCP - 1999" (modalidad: individual, categoría: alumnos).

** A mi madre Teresa, mi hermana Angela y a Mónica, a ellas siempre. 
nal de reconocimiento de las comunidades y sus sistemas de solución de conflictos con la propia existencia de los distintos sistemas de heterocomposición para la solución de conflictos en las comunidades tanto nativas como campesinas

De esta manera observaremos cómo se refuerza el trato a las comunidades dentro de institutos civiles occidentales denominándolas, incluso desde la Constitución Política, «Personas Jurídicas» ${ }^{1}$. Aunque ciertamente la denominación allí empleada no atiende a una definición estricta de tal concepto, adelantaremos que, en su aspiración de insertar por medio del derecho a estas comunidades a la sociedad global se amplía el concepto para adecuar a estos entes colectivos.

Nuestro análisis teórico - metodológico comienza con un desarrollo conceptual de los sistemas de solución de conflictos de autocomposición y heterocomposición, la obligación de los Estados a un servicio de justicia, y el reconocimiento por parte de éste a sistemas propios de solución "la justicia nativa» -, así como la posibilidad de conflicto entre los sistemas al interior del Estado.

En un segundo momento, analizaremos algunos fenómenos jurídicos presentes tanto en las Comunidades como en el resto de la sociedad global. Observaremos la existencia de similares fenómenos y sus diversos tratamientos con el objeto de aproximarnos a ellos y determinar si el sistema se encuentra en colisión o articulación. Finalmente, compartiremos nuestra experiencia en la zona Asháninka, mostrando algunas declaraciones de los nativos.

Sobre esta base, el objetivo de nuestro trabajo consiste en precisar el avance y los alcances de nuestro ordenamiento respecto de las Comunidades, específicamente dentro de las Comunidades nativas Aguaruna y Asháninka. Para ello, tendremos como principal referencia a las ubicadas en el Alto Marañón - en una de las zonas más inaccesibles de la Selva - y a las ubicadas en la Provincia de Chanchamayo - río Perené -, zona en la cual trabajamos una temporada (octubre de 1999).

La perspectiva de análisis de nuestra investigación será, esencialmente, antropológica y jurídica, en la doble vertiente de la costumbre y de la

1 Constitución Política de Perú de 1993 Título III. Capítulo VI denominado: Del Régimen Agrario y de las Comunidades Campesinas y Nativas.

"Artículo $89^{\circ}$.- Las Comunidades Campesinas y las Nativas tienen existencia legal y son personas jurídicas». 
teoría general del Derecho implicados en la cuestión, haciendo uso del Reglamento de Comunidades antes mencionado y de las respectivas normas y conceptos generales de Derecho.

Como ya hemos indicado, el esquema del presente trabajo, que sigue la línea de un desarrollo conceptual, incluye una aproximación al desarrollo legislativo, para posteriormente observar cómo este desarrollo es practicado efectivamente en las Comunidades nativas, llegando a conclusiones que se puedan ampliar a otras situaciones similares. Por tal razón el objetivo final de nuestra investigación consistirá básicamente en una inducción a otros sistemas de alguna de nuestras conclusiones.

Finalmente, $y$ antes de dar pase a nuestro trabajo, agradecemos al doctor Orlando de las Casas de la Torre Ugarte, quien nos brindó su apoyo, compartió sus conocimientos sobre el tema así como a su experiencia en la zona nativa Aguaruna del Alto Marañón y permitió el acceso a una de nuestras fuentes: el Reglamento.

Agradecemos también a Raúl Enrique Miranda Sousa Infante, nuestro amigo que compartió en todo momento el proyecto de investigación en la zona Asháninka, participó en las entrevistas, y colaboró incesantemente en la realización y edición de gran parte de este trabajo. Sin duda alguna, nuestro agradecimiento especial a nuestro maestro Armando Guevara Gil, quien criticó nuestros primeros avances y nos motivó en las nuevas perspectivas sobre nuestras consideraciones hacia el Derecho, a Mariela Cánepa y Zaid Arauco alumnas de Armando Guevara quienes hicieron posible el viaje a la Provincia de Chanchamayo, distrito de La Merced donde realizamos nuestro trabajo de campo hacia el final de octubre y principio de noviembre de 1999.

\section{La naturaleza de la solución de conflictos}

Comenzaremos diciendo que desde la perspectiva de la teoría general del Derecho y específicamente desde uno de los ámbitos de aplicación de ella - la teoría general del proceso -, los seres humanos nos enfrentamos a una realidad natural en el ser humano: la regulación del conflicto.

Debido a la naturaleza de la esencia humana, los seres humanos contienen dentro de sí una necesidad imperiosa por diferenciarse los unos de los otros, por ello la formación de las sociedades y su evolución, unas tan distintas de las otras, no resulta casual. Entonces, el desarrollo de la evolu- 
ción de las distintas sociedades se debe en gran parte a la afirmación de las diferencias sustanciales existentes entre todos los distintos grupos de seres humanos.

Esta noción sobre la cual partimos, la imperiosa necesidad de diferenciarse, permite explicar un fenómeno también consustancial al ser humano: su naturaleza conflictiva. En consecuencia, la regulación del conflicto siempre estará presente, de allí, que la función del Derecho no consista en la utopía de extinguir el conflicto - ello es imposible -; si no, más bien, en la de regularlo y así poder hacer posible la existencia humana de forma pacífica.

Sobre la base de estos presupuestos que conforman la naturaleza del ser humano: diferenciación y conflicto, daremos por sentado que la solución del conflicto se realiza por medio de los sistemas de autocomposición y de heterocomposición.

Los sistemas de autocomposición, son aquellos por medio del cual los seres humanos logran su noción de justicia por mano propia o por la fuerza, logrando la defensa de derechos; es decir, hacen uso de lo que se denomina acción directa; mientras que, en los sistemas de heterocomposición los seres humanos recurren a un tercero a quien facultan e invisten de poder para la solución de los conflictos, en estos casos, se hace uso de lo que se denomina acción civil ${ }^{2}$.

\subsection{Jurisdicción y función jurisdiccional, derecho a la tutela jurisdic- cional. el servicio de justicia estatal}

La evolución de las formas de solución de conflictos va de acuerdo con su aplicación práctica, la cual es distinta atendiendo a la sociedad que lo desarrolla. Sin embargo, desde la perspectiva del Derecho como ciencia universal que pretende regular las conductas sociales para evitar la disociación, contiene una esencia común, aplicable, teóricamente, a todo grupo humano.

2 Sobre la distinción entre acción directa y civil se expresa el profesor Juan Monroy Gálvez. Introducción al proceso civil. Santa Fe de Bogotá. Editorial Temis. Tomo I. 1996, p. 1 - 5; y los citados por el profesor: Eduardo J. Couture, Introducción al estudio del proceso civil. Buenos Aires. Ediciones Depalma, 1978, pp. 16-17; y, Mario Alzamora Váldez. Derecho procesal civil. Teoría general del proceso. Lima. Tipografía Peruana S.A. 1967, p. 1. 
Pues bien, sobre tal base es que se explican los conceptos de jurisdicción, función jurisdiccional y tutela jurisdiccional que a continuación intentaremos dilucidar, con el objeto de no hacer de ellos un, tan frecuente, uso indiscriminado.

\subsubsection{Jurisdicción y función jurisdiccional}

La etimología del término jurisdicción tiene sus orígenes en el Derecho romano. Francisco Hoyos, entre otros, nos recuerda que la palabra jurisdicción deriva del latín jurisdictio, que significa decir o mostrar el derecho (ius dicere) ${ }^{3}$.

Ahora bien, en la modernidad, la mayor cantidad de Estados organizados ejercen el poder a través de funciones. Una de estas funciones es la función jurisdiccional, que no es otra cosa que el servicio de impartición de justicia único, inherente y exclusivo del Estado brindado por medio del órgano denominado, mayormente, Poder Judicial.

Existe pues, una estrecha relación entre los términos jurisdicción y función jurisdiccional. En realidad son dos aspectos de una misma concepción: la heterocomposición en la solución de conflictos de manera válida. La jurisdicción es el aspecto estático del concepto; mientras que, la función jurisdiccional es el aspecto dinámico del mismo. En otras palabras, esta última, mediante el servicio de justicia, hace posible en la práctica a la jurisdicción, por ello ambas forman parte de una misma idea. En consecuencia, conviene comprender lo que es la jurisdicción, pues sabremos que ésta se hará posible por medio del órgano que cumpla su función.

En este punto nos valemos de la definición de nuestro maestro Juan Monroy Gálvez. En palabras del maestro «jurisdicción» es:

"[...] el poder - deber del Estado, previsto para solucionar conflictos de intereses intersubjetivos, controlar las conductas antisociales (faltas o delitos) y también la constitucionalidad normativa, en forma exclusiva y definitiva, a través de órganos especializados que aplican el derecho que corresponde al caso concreto, utilizando su imperio

3 Francisco Hoyos Henrechson, Temas Fundamentales de Derecho Procesal. Editorial Jurídica de Chile. Santiago, 1986, p. 3. Particularmente, consideramos que el concepto de jurisdicción se confunde, muchas veces, con el de competencia que es básicamente la facultad de dar sentencia y poner fin a un conflicto. 
para que sus decisiones se cumplan de manera ineludible, y promoviendo a través de ellas una sociedad con paz social en justicia»"

La definición antes reproducida nos indica un carácter fundamental e inherente a la jurisdicción consistente en la exclusividad. Este carácter tiene directa relación con el principio de unidad de la jurisdicción. Sobre el particular volveremos más adelante al tratar el reconocimiento de los sistemas de solución de conflictos en las Comunidades Nativas.

Por ahora nos centraremos en la relación existente entre la jurisdicción y la competencia. La competencia es definida también por Juan Monroy Gálvez como: «[...] una calidad inherente al órgano jurisdiccional, y [que] consiste en la aptitud para ejercer validamente la jurisdicción» ${ }^{5}$. El citado jurista nos explica que no basta que un órgano jurisdiccional sea tal para que pueda actuar en cualquier proceso válidamente, es necesario que cumpla con cierto número de requisitos, los que suelen denominarse elementos de la competencia.

Hasta el momento queda claro que una de las funciones esenciales de todo Estado es la de impartir justicia de forma única y exclusiva. Esta función se materializa por medio de la función jurisdiccional, a través de la cual se resuelven los conflictos de intereses con relevancia jurídica que pueda darse en la realidad, buscando que la decisión del órgano que la emite sea definitiva y legítima. Luego, se encuentra la posibilidad de ejercer la fuerza pública como un medio para lograr la eficacia de la decisión.

Por consiguiente, resulta contradictorio entender que existen en nuestro ordenamiento fueros privativos o especiales, como jurisdicciones excepcionales, más aún si entendemos que la función jurisdiccional es única y exclusiva. Este es el caso en el que se encuentran los denominados fuero privativo militar y arbitral. Lo cierto es que nos encontramos ante competencias especiales en las que el Estado valida la aptitud de ejercicio de la jurisdicción ${ }^{6}$.

4 Juan Monroy Gálvez, Op. cit., p. 213.

Manifestando una opinión similar y simple, Francisco Hoyos señala que la jurisdicción es «un poder - deber del Estado, que ejercido con sujeción a las formas del debido proceso de derecho tiene por objeto resolver litigios, con eficiencia de cosa juzgada y eventual posibilidad de ejecución». (Cfr. Francisco Hoyos Hen rechson,. Op. cit., p. 5).

5 Juan Monroy Gálvez, "Las excepciones en el Código Procesal Civil peruano». En: Thémis. Lima. No 27 - 28. 1994, p: 122.

6 Consideramos que la normativa en esta materia comete errores en la terminología. Este error incluso se encuentra en nuestra Constitución en el inciso l del artículo $139^{\circ}$ 
No obstante, dejamos en claro que (i) teóricamente pueden no existir los fueros privativos fuera del órgano que ejerce la función jurisdiccional; $y$, (ii) la existencia de los denominados fueros privativos responde a necesidades prácticas de determinadas coyunturas.

Incluimos dentro de los denominados fueros privativos a los sistemas de solución de conflictos reconocidos a las Comunidades Campesinas y Nativas.

\subsubsection{Tutela jurisdiccional}

También entendida como el derecho a la tutela judicial efectiva, la tutela jurisdiccional, encuentra relación directa con el concepto de jurisdicción.

Nos explicamos. Como ya hemos afirmado, la jurisdicción es un poder, pero además es un deber, y es precisamente esto lo que le da contenido, pues el Estado no puede evitar que los distintos sujetos de derecho que lo conformamos exijamos su realización. De esta manera, si un sujeto de derecho lo solicita, el Estado se encuentra obligado a otorgar tutela jurídica para el ejercicio o la defensa de sus derechos o intereses.

En consecuencia, la evolución en las sociedades de los sistemas de solución de conflictos heterocompuestos, permite al Derecho la creación - y a veces recreación - de conceptos tales como jurisdicción, función jurisdiccional y tutela jurisdiccional con el objeto de definir claramente las funciones y obligaciones ineludibles del Estado. De este modo, los Estados brindan un servicio de justicia que permite a los sujetos que lo conforman el arreglo de sus diferencias.

\section{Derecho a la solución de conflictos de las comunidades campesi- nas $\mathrm{y}$ nativas. $\mathrm{El}$ reconocimiento constitucional}

Como ya hemos explicado a partir de los conceptos antes definidos, queda claro que la facultad que el Estado irroga, consistente en el arreglo

cuando entiende que el fuero privativo militar es una excepción en la jurisdicción. Tanto la jurisprudencia, como la doctrina han cometido similar error en el uso de los términos, a tal punto que se ha señalado que la existencia de fueros privativos responde a una excepción en la función jurisdiccional. (Cfr. Pedro Néstor Sagüés, "La jurisdicción militar en Argentina". En: Jurisdicción Militar y Constitución en Iberoamérica. Grijley. 1997, p. 65). 
o solución de diferencias o conflictos, debe ser única y exclusiva, a ello se agrega su carácter de independiente y autónoma. Sin embargo, nuestro ordenamiento jurídico, permite la existencia (coexistencia) de otros sistemas de heterocomposición, que no implican una excepción a la jurisdicción, sino por el contrario permite al propio Estado cumplir con su deber de otorgar tutela jurisdiccional efectiva o simplemente tutela jurídica, por medio de estos sistemas propios.

Así, el desarrollo de sistemas de justicia campesinos y/o nativos, atiende no a una vulneración o excepción a los conceptos de jurisdicción y función jurisdiccional. Por el contrario se vale de ellos y encuentra su validez en el concepto de competencia.

Dicho de otro modo, tanto las Comunidades Campesinas como Nativas al ejercer sus sistemas de heterocomposición, se valen de una facultad que el Estado les proporciona a través de competencias especiales. Entonces, al referirnos a los sistemas de solución de conflictos campesino o nativo, debemos observar que nos encontramos ante competencias que el Estado mismo proporciona con el objeto de hacer posible la tutela jurisdiccional.

\subsection{Diferencia entre comunidad campesina y comunidad nativa. Hacia una definición de comunidad étnica}

Se puede observar que a lo largo de nuestro trabajo hemos empleado conjuntamente el término "Comunidades Campesinas y Nativas». Pues bien, dado que a partir de este punto en adelante, haremos referencia principalmente a las Comunidades Nativas, conviene precisar la diferencia entre ambas.

El tratamiento a los grupos étnicos con organización autónoma y provenientes o naturales de un determinado espacio geográfico, tomó relevancia durante la dictadura militar de los años setenta. Así, como producto de todo un proceso de reforma agraria, los grupos "favorecidos" con las medidas adoptadas fueron precisamente las Comunidades. Por tal razón, el gobierno militar de la época pretendió distinguir a las Comunidades de acuerdo a los ámbitos geográficos en donde se desarrollaban.

Consecuencia de esta pretendida distinción, se crearon dos denominaciones, de un lado, Comunidad Campesina, para distinguir a los grupos de Sierra donde la actividad es predominantemente agraria, y de otro lado, Comunidad Nativa, relacionada a los grupos oriundos de la Selva Alta y 
$\mathrm{Baja}^{7}$. De ahí que haya existido un tratamiento legislativo por separado dirigido a las Comunidades Campesinas en concreto y otro a las Comunidades Nativas.

Como ya hemos advertido, el objeto de nuestro trabajo se centra en los sistemas de solución de conflictos en las Comunidades Nativas. Es por esta razón que nos valemos de las anotaciones de Stefano Varese cuando afirma que:

"Comunidad Nativa es una unidad socio - económica estable, vinculada a un determinado espacio territorial con un tipo de asentamiento que puede ser nucleado o disperso, que se autoreconoce como comunidad y que se diferencia de las otras unidades socio - económicas vecinas, sean nativas o no. De conformidad con la definición puramente operativa, que acabamos de exponer, podemos afirmar que dentro de cada grupo - étnico pueden existir desde dos o tres hasta centenares de comunidades (o grupos locales)" ${ }^{\prime \prime}$. [El resaltado es nuestro].

En consecuencia, la distinción entre Comunidades Campesinas y Nativas es inoperante, ya que no toda comunidad de la sierra puede ser campesina y muchas comunidades de la selva se desarrollan fundamentalmente en la actividad del campesinado. Incluso, la conformación misma de una comunidad denominada nativa o campesina, se semeja a la de un grupo étnico.

Por tal razón, la pretendida distinción bien puede ser calificada como residual. Ergo, la referencia a Comunidades Campesinas o Nativas, en realidad, alude a u grupo étnico reconocido constitucionalmente como tal dentro del cual puede existir más de una comunidad. Por ejemplo: Grupo Étnico Asháninka, contiene a las comunidades del Alto San Miguel de Marankiari y a las del Bajo San Miguel de Marankiari.

Por lo tanto, a lo largo de nuestro trabajo, al hacer referencia a Comunidades Campesinas o Nativas, y, al centrar nuestra atención en estas últi-

7 En el mismo sentido se expresa Susan Harrington cuando afirma que: «La palabra "nativos" se emplea para referirse a individuos pertenecientes a grupos autóctonos que han nacido y crecido en la Selva». Cfr. Susan Harrington Preston. Frente al cambio. Comunidades Nativas de la Amazonía peruana. Instituto Lingüístico de Verano, Lima, 1992.

8 Stefano Varese, "Las sociedades nativas de la selva peruana». En: Las Comunidades Nativas de la Selva. Centro de Estudios de Participación Popular, Lima, abril, 1974, p. 12. 
mas, deberá entenderse la alusión a Grupos Étnicos reconocidos en la constitución bajo las denominaciones Campesinos y Nativos?. Dicho concepto nos permitirá inducir algunas de nuestras conclusiones a los distintos grupos comunitarios que lo conforman yen general a todo el sistema compuesto por aquellos. Sin embargo, debemos agregar que el uso de los términos, Comunidades Campesinas y/o Nativas o Grupo Étnico, será indistinto por lo que nos esmeraremos en no complicar inútilmente la distinción y su uso.

\subsection{El reconocimiento}

Como bien hemos advertido en el punto 1.1 , los conceptos referidos a la jurisdicción y función jurisdiccional contienen dentro de sí un carácter fundamental e inherente consistente en la exclusividad, el mismo que tiene relación directa con el principio de unidad de la jurisdicción.

Pues bien, dicho principio no se vulnera cuando el Estado, por medio de su legislación, reconoce los sistemas de solución de conflictos. Por el contrario, y como también hemos advertido, este reconocimiento permite cumplir al Estado un deber impuesto: la tutela jurisdiccional efectiva, la cual se hace posible con la delegación de facultades para juzgar determinados asuntos a los propios grupos étnicos; es decir, se hace posible mediante la determinación de una competencia que, por la propia naturaleza de los grupos étnicos, es especial.

Existe pues, un acto de reconocimiento por parte del Estado a los sistemas propios de los grupos étnicos de solución de conflictos.

Ahora bien, tal reconocimiento debe siempre atender a una preocupación y reflexión sobre las diversas etnias existentes en nuestro Estado. Un instrumento científico por excelencia para tal finalidad resulta ser la Antropología del Derecho. En palabras del maestro Francisco Ballón:

"La Antropología del Derecho deberá constituirse entre nosotros sobre bases que permitan instaurar en el fondo de sus preocupaciones y como objeto de su reflexión las características multiétnicas y de clase

9 No debe confundirse el uso del término Grupo Étnico para aludir a otros grupos conformados por corrientes migratorias foráneas como por ejemplo: italianos, árabes, judíos, etc., pues estos grupos si bien son étnicos sus sistemas de solución de conflicto no gozan de un reconocimiento constitucional. 
de nuestra sociedad, adscritas a los códigos y a las prácticas estatales» ${ }^{10}$.

Sin embargo, debemos tener presente que todo el avance legislativo, en muchos casos resulta inútil e ineficaz pues no atiende a la realidad concreta. Por tal razón, el citado profesor Francisco Ballón, señala en su obra de análisis de los distintos textos oficiales que tratan el caso amazónico que:

"Los más de dieciocho mil dispositivos legales consignados en estos volúmenes dan cuenta de hasta dónde puede llegar efectiva y concretamente la manipulación del poder aplicado a la realidad Amazónica, una realidad geográfica, social, histórica y económica, atravesada de manera perenne por estos textos legales "sonambúlicos" si se nos permite el adjetivo" ${ }^{11}$.

Así, la manera de acercarse por medio de la legislación a una realidad tan compleja como la Amazónica, ha sido en más de una oportunidad "papel blanco", pues no trasciende las fronteras de la abstracción normativa para llegar a la realidad. A ello debemos sumar la enorme brecha que existe entre los derechos definidos formalmente y las prácticas cotidianas, los mismos que por distintas razones, algunas veces obvias, se acentúan en una población marginada como es la población indígena ${ }^{12}$.

Como sea, lo cierto es que existe un reconocimiento de la existencia de las Comunidades Campesinas y Nativas. Veamos a continuación algo de la evolución de este acto estatal tanto en el ámbito legislativo como en el constitucional.

La Evolución, se inicia en el gobierno militar de la década de 1970, cuando con el objeto de incorporar la colectividad nativa a la vida económica nacional, se emitió el Decreto Ley $\mathrm{N}^{\circ} 20653$, denominado: Ley de Comunidades Nativas y de Promoción Agropecuaria de las Regiones de Selva y Ceja de Selva.

10 Francisco Ballón Aguirre, Etnia y represión penal. Ital, Lima, 1980, p. 33.

11 Francisco Ballón Aguirre, La Amazonía en la norma oficial peruana: 1821 - 1990. Centro de Investigación y promoción Amazónica, Lima, Tomo I. 1991, pp. 13 - 14.

12 Fabiola Luna Pineda, "Participación de las Comunidades Nativas en el desarrollo nacional» En: Desarrollo y participación de las Comunidades Nativas. Centro Amazónico de Antropología y Aplicación Práctica, Lima, julio 1997, p. 22. 
Años después, la Dictadura Militar procedió a "perfeccionar» el citado dispositivo legal mediante el Decreto Ley $\mathrm{N}^{\circ} 22175^{13}$ denominado: Ley de Comunidades Nativas y de Desarrollo Agrario de la Selva y Ceja de Selva. Este nuevo texto derogó al Decreto Ley N² 20653.

Hasta donde hemos podido investigar, el Decreto Ley $\mathrm{N}^{\circ} 22175$ fue el primer dispositivo legal que delegó, mediante su artículo $19^{\circ}$, la facultad (léase: competencia) de solucionar conflictos de forma definitiva. Dicha facultad fue reservada para conflictos y controversias de menor cuantía ${ }^{14}$. Asimismo, entre las normas más importantes del citado texto normativo, se reconoció la existencia legal y personalidad jurídica de la Comunidad Nativa, y del mismo modo, se brindó una definición de ella (artículos $7^{\circ}$ y $8^{\circ}$ respectivamente) $)^{15}$.

Luego, con la Constitución Política de 1979, se reconoció nuevamente a las Comunidades Campesinas y Nativas. Se mantuvo la distinción antes anotada entre Campesina y Nativa; y, se dedicó todo un capítulo a estos grupos colectivos autónomos ${ }^{16}$. Así, en esta ley fundamental se re-

13 El Decreto Ley No 22175 fue publicado el 10 de mayo de 1978 y actualmente se encuentra vigente.

14 Decreto Ley No 22175

"Artículo $19^{\circ}$.- Los conflictos y controversias de naturaleza civil de mínima cuantía que se originen entre los miembros de una Comunidad Nativa, así como las faltas que se cometan serán resueltas o sancionadas en su caso, en forma definitiva por sus órganos de gobierno. En los procesos civiles y penales los Tribunales Comunes o Privativos, según el caso, tendrán en cuenta al resolver, las costumbres, tradiciones, creencias y valores socio culturales de las Comunidadesm.

15 Decreto Ley No 22175

"Artículo $7^{\circ}$.- El Estado reconoce la existencia legal y la personalidad jurídica de las Comunidades Nativas".

"Artículo $8^{\circ}$.- Las Comunidades Nativas tienen origen en los grupos tribales de la Selva y Ceja de Selva y están constituidas por conjuntos de familias vinculadas por los siguientes elementos principales: idioma o dialecto, caracteres culturales y sociales, tenencia y usufructo común y permanente de un mismo territorio, con asentamiento nucleado o disperso".

16 Constitución Política de 1979. Título III. Capítulo VII denominado: De las Comunidades Campesinas y Nativas.

"Artículo $161^{\circ}$.- Las Comunidades Campesinas y Nativas tienen existencia legal y personería jurídica. Son autónomas en su organización, trabajo comunal y uso de la tierra, así como en lo económico y administrativo dentro del marco que la ley establece.

El Estado respeta y protege las tradiciones de las Comunidades Campesinas y Nativas. Propicia la superación cultural de sus integrantes.

Artículo $162^{\circ}$.- El Estado promueve el desarrollo integral de las Comunidades Campesinas y Nativas. Fomenta las empresas comunales y cooperativas. 
conoció su existencia legal, personería jurídica; autonomía para su organización, trabajo comunal y uso de tierras, entre otros.

Posteriormente, el Código Civil de 1984, repitió el reconocimiento efectuado por el texto constitucional y mantuvo las distinciones efectuadas. Básicamente, la regulación más importante estuvo determinada por: (i) la definición como organizaciones tradicionales y estables de interés público, constituidas por personas naturales y cuyos fines se orientan al mejor aprovechamiento de su patrimonio, para beneficio general y equitativo de los comuneros, promoviendo su desarrollo integral (artículo $134^{\circ}$ ); (ii) la obligación de inscripción en el registro respectivo para efectos de su reconocimiento o existencia legal (artículo $135^{\circ}$, en concordancia con el $2024^{\circ}$ ); (iii) el carácter inalienable, imprescriptible e inembargable de sus tierras (artículo $136^{\circ}$ ); y finalmente, (iv) la determinación por parte del Poder Ejecutivo, de su estatuto (artículo $137^{\circ}$ ).

Tanto la norma constitucional del año de 1979, como la legislación del año de 1984, dejaron de lado un aspecto regulado por el Decreto Ley $N^{\circ} 22175$ publicado en el gobierno militar: el reconocimiento a los sistemas de solución de conflictos.

Fue recién con la Constitución Política de 1993 que se da un cambio en esta evolución de reconocimiento a las comunidades. De un lado se les encuadró dentro de una categoría jurídica: la de Persona Jurídica (artículo $\left.89^{\circ}\right)^{17}$; y de otro lado, se dio un importante avance en el reconocimiento, por primera vez en un texto constitucional, del ejercicio de funciones jurisdiccionales (artículo 149 $)^{18}$.

Artículo $163^{\circ}$.- Las tierras de las Comunidades Campesinas y Nativas son inembargables e imprescriptibles. También son inalienables, salvo ley fundada en el interés de la Comunidad, y solicitada por una mayoría de los dos tercios de los miembros calificados de ésta, o en caso de expropiación por necesidad y utilidad pública. En ambos casos con pago previo en dineron.

17 Constitución Política de 1993. Título III. Capítulo VI denominado: Del régimen agrario y de las Comunidades Campesinas y Nativas.

"Artículo $89^{\circ}$.- Comunidades Campesinas y Nativas

Las Comunidades Campesinas y las Nativas tienen existencia legal y son personas jurídicas".

18 Constitución Política de 1993. Título IV. Capítulo VIII denominado: Poder Judicial.

“Artículo $149^{\circ}$.- Ejercicio de la función jurisdiccional por las comunidades campesinas y nativas

Las autoridades de las Comunidades Campesinas y Nativas, con el apoyo de las Rondas Campesinas, pueden ejercer las funciones jurisdiccionales dentro de su ámbito 
De este modo, la evolución de los textos normativos, legales y constitucionales, nos muestra el interés del Estado en reconocer a los distintos grupos étnicos que lo conforman, siendo el reconocimiento más importante y de mayor trascendencia el de los sistemas de solución de conflictos propios a las Comunidades Étnicas.

\section{Posibilidad de conflicto estructural en el sistema de solución de conflictos del estado peruano}

Si atendemos simplemente a la existencia del sistema de solución de conflictos autónomo de las Comunidades, y luego observamos que dentro del Estado también se encuentra el servicio de justicia ejecutado por los órganos del Poder Judicial, se podría percibir la existencia de dos sistemas que cumplen una misma función.

Pues bien, tal apreciación es inexacta y nos puede conducir a error. La existencia del sistema de solución de conflictos atiende a una obligación ineludible de todo estado de derecho. En ese sentido, el reconocimiento de una forma de solución autónoma, como las formas de solución de las Comunidades Étnicas, no significa la renuncia o el cese a su obligación y deber de tutela jurisdiccional. Por el contrario, el acto de reconocimiento, constituye un refuerzo de su acción en busca de tal objetivo (tutela jurisdiccional efectiva). Es más, dicho reconocimiento hace posible el deber. En resumen, los sistemas forman parte de una unidad, por ello coexisten.

Sin embargo, la coexistencia de ambos sistemas nos deja abierta una interrogante: ¿ ¿xiste posibilidad de conflicto estructural en el sistema de solución de conflictos del Estado peruano? Creemos que en tanto el Estado ha buscado y busca "occidentalizar" a los nacionales no integrados y con ello lograr el objetivo de homogeneizar a la sociedad nacional peruana, se está cultivando un contraproducente sistema que evita el progreso de la sociedad misma. A ello se agrega la pérdida de identidad y de patrones culturales propios de una sociedad en su afán de inserción a la sociedad global. El problema se puede observar del siguiente modo: 
«La población indígena amazónica [y en general la población no integrada], presenta una situación general crítica, ya que está expuesta a las graves y permanentes presiones ejercidas por la expansión de las sociedades nacionales que a través de la implantación de políticas económicas incompatibles con el desarrollo sostenible de la región, afecta a los aborígenes a través de procesos de aculturación violentos que transforman rápidamente su vida ${ }^{19}$. [El agregado es nuestro]

Así, el conflicto estructural se genera a partir de una concepción errónea, contraproducente y que vulnera derechos fundamentales reconocidos como son el derecho a la identidad étnica y cultural ${ }^{20}$ y otros.

En ese sentido, la posibilidad de conflicto se ve menoscabada si se mantiene precisamente la diversidad cultural, se afianza íntegramente ésta y se posibilita su desarrollo, se articulan las concepciones allí concebidas a los patrones estandarizados, manteniéndolas firmes y vigentes.

Entonces, para el caso de los sistemas de solución de conflictos la posibilidad de un conflicto estructural pierde presencia cuando los sistemas vigentes se articulan en una misma dirección, precisamente porque a ello está orientado el deber del Estado.

Por el contrario, la posibilidad de conflicto estructural se acrecienta cuando el Derecho mismo se comporta como un medio de imposición de las concepciones de quienes dirigen el Estado frente a un mismo fenómeno. En palabras de Francisco Ballón:

"En el derecho, lo indio, y con ello lo érnico, halla un lugar en el cuerpo de formulaciones operadas por la ideología de la clase dominante ${ }^{21}$.

19 Carlos Yáñez Boluarte, «Retos y posibilidades de los pueblos indígenas amazónicos ante el tercer milenio». En: Desarrollo y participación de las Comunidades Nativas. Centro Amazónico de Antropología y Aplicación Práctica, Lima, julio 1997, p. 43.

20 Constitución Política de 1993. Título I. Capítulo I denominado: Derechos fundamentales de la persona.

"Artículo $2^{\circ}$.- Toda persona tiene derecho:

19. A su identidad étnica y cultural. El Estado reconoce y protege la pluralidad étnica y cultural de la Nación [...]».

21 Francisco Ballón Aguirre, Etnia y represión penal. Op. cit., p. 33. 
Por ejemplo, si los Aguarunas llaman "Manchantukmau» al acto por medio del cual: «Aquél que comete lesión a otro se responsabiliza por los daños", pues debemos mantener su expresión y saber o comprender que se trata de una figura similar (pero con sus particularidades de aplicación por parte de los nativos) denominada en nuestro ordenamiento civil como Responsabilidad; es decir, no debemos intentar insertar figuras o términos técnicos y jurídicos con características de aplicación específicas a un fenómeno tan simple como aquel por medio del cual quien causa un daño lo debe reparar (Manchantukmau o Responsabilidad).

La labor antes señalada, es por demás complicada, - quizá sea la salida a la integración social peruana más completa -, más aún si se tiene en cuenta la variedad de situaciones étnicas propias de nuestra nación, una de las más diversas y diversificadas de la región, a lo que se agrega las diferentes modalidades de contacto entre los grupos étnicos o sociales, los mismos que crean un mosaico de situaciones ${ }^{22}$.

Lo antes seńalado es expresado desde el punto de vista de Carlos Yáñez del siguiente modo:

«La Constitución Política vigente reconoce por primera vez de manera explícita el carácter multiétnico y pluricultural de la Nación Peruana. Pese a ello el derecho a la diferencia, a la especificidad cultural, a pertenecer a la misma sociedad con códigos, lenguajes y valores propios, aún no es comprendido cabalmente, por ello pensamos que éste será un tema importante en el debate nacional. El reconocimiento implica la aceptación de que existen diversas culturas en la sociedad con igual capacidad de acción, con iguales derechos, con igualdad de valores ${ }^{23}$.

En consecuencia, en el proceso de integración de la nación peruana y en el mantenimiento de la diversidad y afirmación de las identidades, la lenta transformación nos llevará a la reformulación de nuestro concepto

22 Stefano Varese, "Notas sobre el autogobierno en las sociedades nativas de la Selva". En: Las Comunidades Nativas de la Selva. Centro de Estudios de Participación Popular, Lima, abril 1974, p. 86. En el mismo texto, el autor señala que: «[...] la sociedad nacional como un conjunto, está muy lejos de funcionar orgánicamente como una estructura de complejos sociales relativamente integrados".

23 Carlos Yáñez Boluarte, Op. cit., p. 49. 
de sociedad peruana, evitando con ello el aislamiento de los grupos étnicos de la sociedad global que los encierra sin imposición de condiciones estructurales ya sean sociales, económicos, políticos y culturales.

\section{Concordancia de los sistemas de solución de conflictos en el estado peruano}

En vista que los sistemas vigentes de solución de conflictos no se encuentran precisamente en oposición, cabe la labor de articularlos. La articulación de dichos sistemas evita el conflicto estructural al interior de un Estado, permite su afirmación en las sociedades y logra el progreso tan ansiado en las sociedades que así lo exigen. Es por ello, que en busca de una articulación de los sistemas conviene analizar los términos en que está expresado este Derecho diverso y especial en busca de mantener y lograr dentro de su diversidad la unidad.

\subsection{El sistema de solución de conflictos de las comunidades nativas. el análisis concreto}

Sabido es pues, que el ordenamiento jurídico nacional propone, mediante el reconocimiento, una forma de autogobierno a los grupos o estamentos sociales semiautónomos. Precisamos que entendemos el concepto de estamento social semiautónomo como aquel grupo que mantiene dentro de sí un sistema propio de reglamentación de las conductas sin necesidad de alejarse de los lineamientos generales que establece el Estado.

Así por ejemplo, la Universidad deviene como grupo social semiautónomo, pues regula dentro de su ámbito de relaciones las conductas y acciones de los individuos que la conformamos. Claro está que tal forma de regulación no debe estar alejada de los principios que ordenan el Estado.

En ese sentido, el reconocimiento de su autonomía, no exonera a aquélla de su obligación de mantener vigentes dentro de su propio ordenamiento las pautas generales que inspiran el ordenamiento global.

Lo antes dicho tiene singular relevancia cuando analizamos al interior de los grupos sociales semiautonómos el tema de solución de conflictos. Así, no todo grupo social -en el caso de investigación: los grupos étnicos -, ostenta el reconocimiento a un sistema de solución de conflictos. 
Siguiendo el ejemplo de la Universidad, ésta se encuentra supeditada al ordenamiento jurídico global, pues entre otras cosas se encuentra inmersa dentro del sistema, es decir, está integrada. En ese sentido, sus formas se encuadran dentro de lo que el sistema denomina: sistema administrativo o vía administrativa.

Lo cierto es que en las Comunidades Nativas, se regula las conductas sociales como en cualquier otra sociedad. Asimismo, el método de hacer valer las decisiones es la coerción por medio de la sanción social. En consecuencia, cuando el sistema basado principalmente en soluciones consuetudinarias no cumple con la sanción, recurren al sistema de servicio de justicia estatal, por ser éste de mayor estructura, y por considerarlo como un sistema que se encuentra por encima del sistema de la comunidad.

Dicha observación es también compartida por el Centro de Investigación y Promoción Amazónica - CIPA, cuando en sus experiencias con las Comunidades Nativas observaron una regla:

"Los Jueces resuelven cuando no nos ponemos de acuerdo entre nosotros acerca de nuestros derechos o si se trata de sancionar a alguien por incumplir las leyes $)^{24}$.

Ahora bien, retomando la noción de autogobierno, debemos decir que son diversas las razones que permiten la regulación en las Comunidades Nativas. A partir de las señaladas por Stefano Varese ${ }^{25}$, en nuestro criterio son dos las más importantes:

(i) La resolución de conflictos directamente y a través del control social que se da en toda comunidad y se ejerce en las relaciones diarias cara a cara; $y$,

(ii) Debido a que se ejerce un tipo de democracia de participación ya que todos y cada uno de los miembros de la comunidad tienen y practican el derecho de opinión.

En efecto, los miembros de la comunidad, ejercen un tipo de control social entre sí y además cumplen una labor plenamente participativa de los lineamientos, políticos, sociales, económicos dentro de la organiza-

24 Centro de Investigación y Promoción Amazónica - CIPA, Derechos de las Comunidades Nativas y de sus Miembros. CIPA, Lima, 1985, p. 23.

25 Stefano Varese, "Notas sobre el autogobierno en las sociedades nativas de la Selva». En: Las Comunidades Nativas de la Selva. Centro de Estudios de Participación Popular, Lima, abril 1974, p. 91. 
ción comunal. Las decisiones se toman entre todos. Además sus métodos de solución tienen un reconocimiento especial y distinto al de otros grupos sociales semiautónomos.

\subsection{Institutos comúnmente regulados en algunas comunidades nativas}

Con la finalidad de articular los sistemas, nos aventuramos a trabajar algunos fenómenos que han sido destacadamente estudiados por el Centro de Investigación y Promoción Amazónica - CIPA, en el Reglamento de Administración de Justicia Nativa, e intentado por nuestro trabajo de campo en la zona Asháninka.

Ya hemos expresado en nuestra introducción al presente trabajo que, el reglamento aparece como una suerte de codificación de los fenómenos sociales por regularse en la Comunidad Nativa Aguaruna. A ello, agregamos la experiencia sobre el terreno obtenida en la interacción de nuestra parte con los Asháninkas. En ambos casos hemos percibido, la regulación similar de fenómenos tan comunes y presentes en toda sociedad como son: la unión de un varón y una mujer con el objeto de hacer vida en común, la separación del varón y mujer antes unidos y formados en vínculo, la responsabilidad que dicha separación genera, los casos de extinción de la vida y los de sustracción de bienes patrimoniales de un sujeto a otro.

Pues bien, dichos fenómenos son apreciados y valorados de manera distinta dependiendo de la sociedad en la que nos encontremos. Ello precisamente debido a que las diferencias consustanciales de los sujetos que las conformamos varían de acuerdo a cada sociedad.

Lo cierto es que los fenómenos son los mismos y la valoración por el grupo es distinta. En consecuencia, cabe entender el fenómeno y analizar el tipo de valoración y apreciación, que da cada grupo a fin de lograr la protección real de los derechos allí existentes. De este modo, el sistema encuentra una afirmación de las características especiales asignadas al fenómeno de acuerdo a la valoración del grupo y su articulación con las del resto de la sociedad.

La consecuencia de este tipo de acto, no es otra que la de entender como se identifica un mismo fenómeno desde ambas perspectivas, sin necesidad de imposición de una sobre otra, ni de inserción de terminologías y precisiones (en nuestro caso técnico jurídicas) distintas a las consideradas en el grupo social que se pretende insertar. 


\subsection{El caso de las comunidades nativas del Alto Marañón. los Aguarunas y su reglamento.}

El área de asesoría legal del Centro de Investigación y Promoción Amazónica - CIPA con el objeto de lograr un avance en fuente escrita, iniciado por los propios Aguarunas, concibió el denominado «Reglamento de Administración de Justicia Nativa» (chicham utugchat epegkatasa umikmau ${ }^{26}$, como un instrumento de justicia practicada por los ancestros que además permitiese el progreso cultural de la etnia.

A continuación, observaremos cómo han sido recogidos y regulados algunos fenómenos sociales.

\subsubsection{Matrimonio}

La institución del matrimonio es el primer instituto o fenómeno aludido en el Reglamento. Sin embargo, la regulación no es directa; es decir, no propone una definición de matrimonio o de los deberes y derechos existentes durante la relación conyugal. Por el contrario los principales aspectos allí recogidos están dirigidos a los aspectos que pueden generar conflictos entre las partes conyugales.

El matrimonio es el tema de mayor tratamiento en el reglamento. Abarca diecisiete artículos y es el primer capítulo del Reglamento.

Aspectos relacionados con el inicio del matrimonio ${ }^{27}$ como son: (i) el matrimonio de menores de dicciocho años de edad quienes no están obligados a contraer casamiento, ni aún cuando los padres así lo consideren y (ii) el matrimonio con "extranjeros", quienes al contraer la unión se deben someter al reglamento pues de lo contrario la Asamblea decide el lugar donde van a vivir.

26 A lo largo de este punto, entenderemos «el Reglamento" por nuestra fuente "Reglamento de Administración de Justicia Nativa" (chicham utugchat epegkatasa umikmau).

27 «Artículo $12^{\circ}$.- La persona que se case tendrá que hacer público su matrimonio y lo hará conocer al Jefe de su Comunidad.

Artículo $11^{\circ}$.- Los menores de dieciocho años de edad, no tienen por qué casarse aunque lo quiera su padre.

Artículo $14^{\circ}$.- Cuando un mestizo se case con una nativa deberá someterse al Reglamento Interno de la Comunidad. En caso de no hacerlo, la Asamblea decidirá donde van a vivir". 
Un aspecto que llama la atención y que se encuentra regulado durante la relación conyuga ${ }^{28}$ es la poligamia.

Finalmente, los aspectos que ocupan la mayor regulación de este instituto son los aspectos relacionados con la extinción del vínculo ${ }^{29}$. Se regulan aspectos tales como: la separación de cuerpos, el destino de los hijos en caso de separación (lo que nuestro código civil regula a través de la patria potestad), las responsabilidades respecto de los hijos, el cuidado de ellos, fenómeno denominado y conocido como alimentos.

En la regulación, encontramos, en cuanto al fondo, características comunes a las tratadas en el Código Civil y a su vez, diferencias saltantes. La concepción de matrimonio es similar en cuanto consiste en la unión de varón y mujer, y es disímil en cuanto a la posibilidad de mantener más de una relación o vínculo.

Encontramos coincidencias con el ordenamiento occidental, en lo que se refiere al reconocimiento de los hijos y, la existencia de una regulación especial en el caso de matrimonio de menores.

Se puede observar que, el Reglamento le da mucha importancia a la actuación de los padres de los esponsales en el desarrollo normal y en la solución de conflictos dentro de la institución del matrimonio, por ejemplo, el artículo $16^{\circ}$ señala:

"Artículo $16^{\circ}$.- Ningún comunero puede contraer matrimonio sin autorización de su padre. Si no existiese aceptación de parte del padre de la mujer sobre su casamiento y el interesado la persigue será detenido por la familia hasta que sea reclamado por su padre».

Este artículo nos demuestra claramente la importancia y la participación de los padres en la decisión de contraer una unión. Así pues, la carac-

28 "Artículo $6^{\circ}$.- El hombre que estando casado, contrae otro matrimonio, asume todas las responsabilidades».

29 «Artículo $1^{\circ}$.- El varón o la mujer que quiere separarse de su esposa (o) tendrá un plazo de 6 meses o según el acuerdo de sus familiares, la denuncia será puesta ante el despacho del Jefe de la Comunidad.

Artículo $2^{\circ}$.- En caso de separación de preferencia la madre se quedará con sus hijos. Si se casa nuevamente según la edad de sus hijos y conversaciones entre los padres, se verá quien de ellos se responsabiliza de su cuidado.

Artículo $8^{\circ}$.- El hombre que habiendo embarazado a una mujer no quiere casarse con ella será sancionado con castigo de seis días de calabozo y tiene la obligación de reconocer al hijo». 
terística que observamos a partir de este artículo y aquél que determina que los menores de dieciocho no tienen por qué casarse aunque lo quiera su padre [véase la nota al pie 27] es que de un lado, los padres autorizan el matrimonio y de algún modo varían nuestra concepción sobre el mismo, dejando de ser la unión un acto independiente y voluntario de los sujetos inmiscuidos pues requiere la aprobación o autorización - consentimiento - de los padres; de otro lado, los padres no pueden obligar a contraer matrimonio a los menores.

Como ya hemos observado, la diferencia más saltante dentro de esta regulación es la permisión de la poligamia. En efecto, el artículo $6^{\circ}$ señala lo siguiente:

"Artículo $6^{\circ}$.- El hombre que estando casado, contrae otro matrimonio, asume todas las responsabilidades».

Ahora bien, dentro de las comunidades Aguarunas esta figura se permite «siempre y cuando el varón tenga posibilidades económicas. Si ello ocurre, entonces el varón no sólo contrae matrimonio con más de una mujer sino que se le inserta una obligación: hacerse responsable; además incluso se llega a "ver con malos ojos" al Aguaruna varón que sólo tenga una esposa ${ }^{30}$.

Esta clase de regulación, dista de nuestro ordenamiento impuesto por el código civil. Aquí sí se vislumbra una posibilidad de conflicto estructural, ya no por la existencia del sistema de solución de conflicto, sino por los propios institutos regulados.

Con respecto a la patria potestad de los hijos de padres separados el Reglamento señala que éstos se quedarán bajo custodia de la madre, lo que también se diferencia claramente a lo expuesto en el Código Civil donde se señala que, en primera instancia, los hijos se quedarán con el padre que no incurrió en la causal de separación. Asimismo, se protege a los hijos cuando la madre se case nuevamente e incluso se da la posibilidad que la patria potestad sea ejercida por el padre, dependiendo de la edad de los hijos y de las conversaciones que se den en ese sentido.

30 Referencia del Dr. Orlando De las Casas De la Torre Ugarte sobre sus experiencias en relación con el grupo étnico Aguaruna. 


\subsubsection{Divorcio}

Este instituto o fenómeno social es atendido dentro del capítulo dedicado al Matrimonio, del siguiente modo:

"Artículo $1^{\circ}$.- El varón o la mujer que quiere separarse de su esposa (o) tendrá un plazo de 6 meses o según el acuerdo de sus familiares, la denuncia será puesta ante el despacho del Jefe de la Comunidad

Artículo $2^{\circ}$.- En caso de separación, de preferencia la madre se quedará con sus hijos. Si se casa nuevamente según la edad de sus hijos y conversaciones entre los padres, se verá quien de ellos se responsabiliza de su cuidado".

La regulación es simple y no establece motivos para que se exprese la voluntad de separarse, simplemente se hace posible mediante la voluntad sin expresión de causa y sin inserción dentro de una causal establecida previamente. Aquí hay una gran diferencia con el resto de nuestro ordenamiento jurídico, que señala expresamente los motivos o causales por medio de las cuales los sujetos unidos pueden separarse.

Como podemos observar se han regulado también los efectos que produce esta figura respecto de los hijos. Tal y como hemos anotado en el punto anterior existe una clara diferencia a lo normado por el Código Civil donde se señala que, en primera instancia, los hijos se quedarán con el padre que no incurrió en la causal de separación ${ }^{31}$.

\subsubsection{Homicidio}

En este punto encontramos una particularidad y a la vez un gran impedimento. En el reglamento resalta dentro de la regulación el tratamiento a una figura compleja y delictiva como es el homicidio, sin embargo, poca información hemos podido obtener en relación con esta figura. En ese sentido, dejamos abierto el tema con el objeto que sea profundizado.

31 Código Civil de 1984. Libro III del Derecho de Familia. Sección Tercera. Título III. Capítulo Único.

"Artículo $420^{\circ}$.- En caso de separación de cuerpos, de divorcio o de invalidez del matrimonio, la patria potestad se ejerce por el cónyuge a quien se confían los hijos. El otro queda, mientras tanto, suspendido en su ejercicio". 
Y es que no sólo se trata de una figura delictiva compleja y de enormes repercusiones en toda sociedad sino que ciertamente, la regulación es obscura debido a que no existe traducción oficial; por el contrario, deliberadamente se ha omitido su traducción en el Reglamento ${ }^{32}$.

La regulación en el idioma de los Aguarunas versa así:

"MAGKAGTUAMUNUM

Artículo $39^{\circ}$.- Magkagtuamun, utugchata epegkin diyakug atus umikti.

Apun ijumag ausati.

Pataintinum ijumag ausati.

Epegkeamunak utugchatan epegnujai inagnakti.

Artículo $40^{\circ}$.- Jakau patayi ujankati, bitaikan kuitamkatnume tusa".

Especulamos que, la omisión de la traducción, ha de deberse al tipo de sanción destinado, considerado como un exceso dentro de las competencias que se le asigna a los sistemas de solución de conflictos.

\subsubsection{Robo}

En lo que respecta a la sustracción de bienes de un patrimonio a otro, la regulación nativa no hace distinción en el acto; es decir, si el acto de sustracción es realizado con violencia o sin violencia.

Esta distinción en el resto del ordenamiento tiene relevancia para la calificación del propio acto, es decir, determina si nos encontramos ante el robo (sustracción empleando medios violentos) o el hurto (sustracción sin empleo de medios violentos).

"Artículo $18^{\circ}$.- Toda persona que roba animales, plantas, y otros, deberá pagar el valor de lo apropiado.

Para el castigo se le aplicará el humeo en la cara y la toma de ayahuasca».

La regulación antes transcrita resalta el tipo de sanción y la calidad de la misma dentro del orden Aguaruna. Es decir, nos proporciona una ventana de observación del sistema de valores y medios de prevención general de actos antisociales.

32 Declaración del Dr. Orlando De las Casas De la Torre Ugarte acerca de los Aguarunas. 
Existen otros medios de sanción dentro de la comunidad tales como el calabozo y el trabajo comunal, ellos también nos dejan abierto un análisis sobre el tipo de valor social de las sanciones. Tales estudios, por su amplitud, no corresponden al presente trabajo.

\subsection{El caso de las Comunidades Nativas del Perené. Los Asháninkas de San Miguel de Marankiari.}

La Comunidad Nativa Asháninka de San Miguel de Marankiari está ubicada en la zona del río Perené, km. 26 de la Carretera central marginal vía La Merced a Satipo; cuenta con un clima tropical, caluroso, húmedo y lluvioso de temperaturas que oscilan entre los 23 y 38 grados celsius.

Esta comunidad conformada en la actualidad por alrededor de sesenta familias, fue fundada hacia el año 1950 por el señor Miguel Samaniego, consta de un área de $147 \mathrm{Has}$. en donde la principal actividad que desarrollan sus pobladores es la del cultivo de piñas, plátanos y otros.

Ya hacia 1980, obtuvieron el reconocimiento como comunidad nativa procediendo a registrar los terrenos a nombre de la comunidad, concluyendo las disputas con colonos de la zona. Cabe mencionar que esta comunidad forma parte de las cuatrocientas comunidades indígenas del Gran Pueblo Asháninka.

En la actualidad, la Comunidad de San Miguel perteneciente al grupo étnico Asháninka está tratando de rescatar todo aquello que forme parte de su cultura. Debido a la enorme forma en que las relaciones sociales se multiplican y globalizan, las relaciones de toda sociedad se muestran inmersas a este fenómeno mundial; sin duda alguna, las sociedades nativas también forman parte de este fenómeno. Ello motiva a que los comuneros consideren su interrelación sin pérdida de su identidad ${ }^{33}$.

Sobre el particular, compartimos lo expresado por Margarita Benavides:

"La organización política es potenciada, en el caso de los Asháninkas por la cohesión del grupo étnico, a través de un sistema flexible de extensas relaciones de parentesco y por la reafirmación de su identidad $»^{34}$.

33 A decir del Jefe de la Comunidad Nativa: «[...] estamos mezclándonos, pero mantenemos nuestra identidad [...] estamos tratando de rescatar todo en lo que consiste nuestra cultura Asháninka».

34 Margarita Benavides Matarazzo. «Autodefensa Asháninka, organizaciones nativas y 
A continuación, compartiremos nuestra experiencia con el grupo nativo Asháninka de San Miguel de Marankiari y mostraremos cómo han regulado fenómenos sociales antes analizados para el caso de las Comunidades Aguarunas del Alto Marañón aún cuando carecen de un Reglamento de Administración de Justicia Nativa ${ }^{35}$.

\subsubsection{Matrimonio}

En nuestro acercamiento a las formas de normar algunos fenómenos sociales descubrimos en relación con el matrimonio que las ceremonias propias de matrimonio no son practicadas por esta Comunidad Asháninka.

Ello no implica la extinción de una costumbre, pues en otras comunidades se debe mantener la ceremonia y forma de unirse del varón y de la mujer.

En su lugar los comuneros han recurrido al sistema de derecho externo, sin que ello implique una integración total por parte de ellos a la sociedad global. Cuando preguntamos sobre el matrimonio en la Asamblea Comunal nos dijeron:

"Las ceremonias de matrimonio ya no las practicamos, ahora el matrimonio es civil. Esas costumbres no las mantenemos.

$[\ldots]$

Si se quieren casar entonces vamos al pueblo, nos dirigimos al Alcalde y contraemos matrimonio por lo civil ${ }^{36}$.

A diferencia del caso Aguaruna, en aquella comunidad se presupone la existencia de un instituto por medio del cual se unen varón y mujer ya que dicha unión incumbe la participación de los padres en la aprobación y existe una forma específica de disolución del vínculo.

Sin embargo, la comunidad es consciente de la importancia de la unión de varón y mujer y muestra su preocupación en relación con el matrimonio. Así a decir del Jefe de la Comunidad:

autonomía indígena». En: Perú: el problema agrario en debate. SEPIA, Lima 1992, p. 556.

35 Preguntamos al Jefe de la Comunidad Nativa: «Tienen reglamento de Administración de Justicia?" Y nos respondió: "No, no tenemos».

36 Declaración del Jefe de la Comunidad Nativa en la Asamblea Comunal del 30 de octubre de 1999. 
"Nosotros tenemos la idea que, nuestros hijos son nuestros amigos y hacerles presentes que si están dispuestos ha contraer matrimonio, entonces deben ser responsables y asumir el futuro [...]

Al asumir la responsabilidad a la persona se le presenta un reglamento donde se dice que debe cumplir con tales formas ${ }^{37}$.

Ello nos demuestra que el instituto mantiene, aún cuando se desarrolla por vía externa, particularidades propias para el ejercicio dentro del grupo social.

La Comunidad objeto de análisis se ha visto enormemente influenciada por patrones culturales externos al propio grupo étnico Asháninka, pues a decir de sus representantes:

"Antes no interesaba la edad para casarse, hoy con el transcurso de los tiempos estamos actualizando las cosas y ahora se ven las parejas de 19,20 años $"^{38}$.

Esperamos que en las interrelaciones sociales y en su propósito de mantener su identidad, el pueblo Asháninka de San Miguel de Marankiari recupere una costumbre que ha perdido vigencia entre ellos: la ceremonia de matrimonio y con ello la forma consuetudinaria y particular de unirse el varón y mujer miembros de la comunidad. Nuestro ideal se sustenta en que la inserción cada vez más latente no implique de ninguna manera la pérdida de identidad, de valores propios y culturales, ni de prácricas consuetudinarias que mantienen la diversidad de nuestra nación; pues de lo contrario, se generaría la pérdida para la nación peruana de una comunidad más dentro de un gran grupo étnico como es el gran pueblo Asháninka.

\subsubsection{Divorcio}

Nuevamente, nos enfrentamos a un vacío dentro de la comunidad objeto de análisis. No obstante, no dejaremos de analizar el punto. Nos explicamos. Quizá por la cohesión del grupo se niegue la existencia de una realidad o quizá el fenómeno haya encontrado una forma de solución 
no prevista en la disolución del vínculo creado, debido a que el instituto se celebra según los patrones externos pero se ejerce dentro de los patrones culturales propios creando - recreando - de esta manera una forma no contemplada en el ordenamiento jurídico global de solución del problema con efectos disolutivos del vínculo creado.

El divorcio es considerado como un tipo de maldad que no es compartida ni ejercida dentro del grupo comunal nativo. Tan es así que cuando dentro de un matrimonio existen problemas que tiendan a la separación y ruptura del vínculo, la comunidad ve con preocupación este tipo de actitudes y busca mantener evitarlas prefiriendo la unión de la familia a su desunión. Esto fue lo que nos dijeron:

"Nosotros, la Directiva, nos vamos a reunir con la pareja, con el objeto de saber la razón de la separación. Quizá el problema tenga sus orígenes en la falta de consejos de personas mayores.

[...] para el matrimonio tiene que existir el amor. Si se han juntado entonces continúen, así se empieza y se debe continuar.

$[\ldots]$ nunca hemos tenido esos problemas" ${ }^{39}$.

Quizá también la forma de solución no prevista se conduzca de acuerdo a la regulación Aguaruna, basándose en un acuerdo de los sujetos unidos por el vínculo, sin la existencia de un grupo de causas por las cuales sea viable la disolución.

Sin embargo, en vista de la falta de un hecho de disolución de vínculo matrimonial, no es posible conocer los efectos que generaría tal situación y compararlos luego con el resto del ordenamiento civil. Suponemos además, que la forma de establecer los efectos sobre la patria potestad se determinará con la ayuda y remisión a otras figuras tales como casos de abandono o de fallecimiento de ambos padres.

\subsubsection{Homicidio}

Otra vez, nos enfrentamos a un vacío empírico, del cual obtendremos algunas deducciones. En la entrevista al Jefe de la Comunidad conseguimos la siguiente información: 
«Alguna vez han tenido un caso de homicidio?

- Aquí nunca, [...] nada.

Si se diera el caso [esperamos que nunca ocurra], ¿Ustedes mismos emitirían la sanción o lo remitirían a las autoridades?

- En esos casos nosotros ya no podemos ver. Nosotros mismos determinamos hasta donde podemos solucionar, pero esos casos son muy graves y no podríamos ver el tema $»^{40}$.

Como se puede observar existe un límite impuesto por la propia comunidad nativa, que no permite el desarrollo de su actividad reconocida por el Estado. Se deja abierta pues una cuestión: ¿̨Cuáles son los límites de la «Justicia Étnica»?

Ciertamente, los límites vienen resueltos por fronteras empíricas y no sistémicas. En cualquier caso, los límites debieran estar determinados por los temas de Competencias Expresas para el ejercicio de las facultades jurisdiccionales reconocidas a la justicia nativa y campesina.

En otras palabras, en vista de la inexistencia de límites expresos y basados en límites empíricos, correspondería determinar los límites en virtud de la competencia especial que ostentan dentro del único sistema jurisdiccional que opera en el Estado. [Véase el numeral 2 del punto I].

\subsubsection{Robo}

El caso de sustracción de bienes con valor patrimonial ha sido directamente tratado por la Comunidad nativa objeto de análisis.

Así en caso de "robo", se reúne la Directiva Comunal con el objeto de llamar la atención al sujeto activo para el cese de los actos. Ya en casos de reincidencia, se ingresa en todo un procedimiento seguido contra el sujeto que consiste en lo siguiente:

(i) Reincidencia de robo: se emite ante la Directiva Comunal o el Jefe de la Comunidad Nativa, un acta en donde consta la acusación.

(ii) Se convoca a una reunión general (Asamblea General Extraordinaria) de los miembros de la comunidad con el objeto de determinar la sanción.

(iii) En caso de incumplimiento de la sanción y/o reincidencia se remite el caso a las autoridades judiciales. 
Nuevamente, observamos el recurso a autoridades consideradas por los propios nativos como superiores.

\subsection{El trabajo de campo en la región de los Asháninkas de San Miguel de Marankiari}

En este punto pretendemos compartir nuestra visión sobre la Comunidad nativa visitada en octubre de 1999. A fin de conocer las impresiones de los nativos, entrevistamos al Jefe de la Comunidad y a algunos pobladores con el objeto de captar distintas versiones, la del representante oficial y la de los propios actores sociales.

5.5.1 Entrevista al jefe de la comunidad nativa sobre el sistema de solución de conflictos.

Fueron diversas las preguntas que hicimos al Jefe de la Comunidad. Aquí transcribimos las que hemos considerado convenientes:

"Ustedes tienen un listado de sanciones o las determinan de acuerdo al caso concreto?

- Aquí las sanciones son como limpieza, trabajos a favor de la comunidad, se ve dependiendo el caso».

La Comunidad no tiene un catálogo de sanciones puesto que no ha reglamentado aún su sistema de derecho consuetudinario.

Tal y como ya hemos referido, el sistema de solución implica un medio de sanción social que pueda funcionar efectivamente sobre los miembros, de tal suerte que existe una fuerte prevención social de las conductas que no van acorde con el orden común. En ese orden de ideas:

«¿Cuál es el castigo más severo que hay en la Comunidad antes de remitir el caso a las autoridades?

- El castigo es tirar látigos, este castigo está destinado a personas mayores, pero no hemos llegado a esto; $y$,

- En caso de menores de edad se reúne la Directiva con los padres y el menor».

La comunidad reconoce como autoridades a quienes imponen las sanciones, ello se desprende de lo siguiente: 
"¿Quiénes imponen la sanción?

Las autoridades del lugar, Jefe de la Comunidad, Agente Municipal, y antes de la subversión existían Tenientes Alcaldes".

5.4.2 Entrevista a algunos de los miembros de la comunidad nativa respecto del sistema de solución de conflictos.

Con el objeto de observar las declaraciones directas de los propios actores sociales, realizamos diversas entrevistas a los miembros de la Comunidad.

En esta labor, fue extraño para nosotros cuando uno de los comuneros nos remitió a la autoridad competente, como si sólo pudiese manejarse frente a terceros una versión oficial de las cosas y no entrar en contradicho.

Sin duda alguna, nuestra interacción con los comuneros se vio limitada por el tiempo, no obstante ello, la percepción de lo antes dicho se vislumbra en el manejo de los comuneros con los terceros. ¿Permiten estas comunidades que se les conozca a profundidad?. La interrogante queda también abierta, no obstante, consideramos que mostrarse como un bloque, en cohesión, articulado, es una herramienta de todo grupo social frente a terceros.

Aquí las entrevistas con mayor contenido:

Entrevista al señor Orlando Sixto:

«Señor, ¿Cuál es su nombre?

- Orlando Sixto.

¿Cuáles son los típicos problemas entre pobladores?

- No aquí no hay problemas, nunca hay nada. Nosotros vivimos tranquilos.

¿Nunca hay robos, separaciones?

- No. No

¿Quizá, problemas de tierras?

- No tampoco, porque aquí somos una comunidad y no hay porque tener esa clase de problemas

¿Ustedes suelen tener problemas con extraños?

- Si siempre sólo tenemos problemas con extraños aquí los comuneros son todos tranquilos.

¿Cuándo hay problemas a quién recurren? 
- Normalmente al jefe de la comunidad y si no se puede arreglar acá, vamos a la autoridad competente, vamos al juez

Aquí los problemas más frecuentes son de dichos y entre vecinos».

\section{Entrevista al señor Demetrio Calep:}

«Señor, ¿Cuál es su nombre?

- Demetrio Calep

¿Cómo solucionan sus problemas?

- Cuando hay problema, vamos al jefe. De acuerdo a la gravedad del problema, ya que, se va a la autoridad judicial.

¿Cuáles son los problemas más frecuentes?

- Cuando hay robos, otros problemas menores.

¿Cuáles recuerda?

- Yo no he tenido problemas, los problemas más comunes son los vecinales, como por ejemplo, calumnias. Todo trata de llegar a arreglar la vecindad.

¿La forma de solución es de acuerdo a la gravedad recurrir al jefe y en mayores casos al juez, le parece adecuada?

- Hay veces queda aquí. Nosotros arreglamos nuestros problemas aquí en la comunidad, reconocemos nuestra falta.

¿Una parte de la comunidad es católica y la otra es adventista, hay problemas entre ustedes por este motivo?

- Un 30\% de la comunidad está en la iglesia adventista. El resto somos católicos, pero en faenas todos colaboramos, y a los que no colaboran se les ignora. Todos los cristianos, somos colaboradores. ¿Estos problemas llegan hasta el jefe de la comunidad?

- Hay veces queda aquí. Nosotros arreglamos nuestros problemas aquí en la comunidad, reconocemos nuestra falta.

- No esos problemas no llegan lo solucionamos nosotros no más. Ellos siempre se mantienen al margen del resto de la comunidad, salvo en las faenas."

En resumen, debemos mencionar que la comunidad nativa de los Asháninkas de San Miguel de Marankiari, se muestra como una sociedad ideal, en donde los medios de prevención se han mostrado eficaces y las conductas antisociales se encuentran desterradas, sin embargo, no creemos que ello sea tan cierto, en vista de que la propia comunidad mantiene 
bajos niveles económicos, una extensión territorial de sólo 147 has. para 60 familias que están en aumento poblacional y una división interior entre católicos - todos colaboradores - y protestantes - que siempre se mantienen al margen -. Tal división interior podría llevar a una escisión de la propia comunidad.

\subsubsection{Finalmente...}

Sabido es que los fenómenos sociales se presentan, en esencia, similares en las sociedades y son éstas las que le insertan particularidades propias que presentan al fenómeno como un todo complejo y a veces totalmente opuesto, debido a la evolución o a la propia consideración del fenómeno. Lo cierto es que debemos lograr entender los fenómenos, analizando las similitudes y diferencias, más aún cuando nos encontramos a esencias similares, unión, consentimientos, responsabilidades, etc. Estas acciones permiten lograr un importante paso hacia la articulación de todo un sistema social, político, económico, jurídico y cultural.

No nos enfrentamos pues a una necesidad de homogeneizar a la sociedad peruana, tan diversa en sí misma, se trata de articular y mantener la diversidad y de comprender los fenómenos sociales a la luz de los propios ordenamientos, comprender a los distintos grupos que manifiestan tanto la multiculturalidad de nuestro Estado, como el pluralismo legal existente.

En otras palabras, estamos en busca pues, de encontrar un ordenamiento jurídico nacional que reconozca (sin necesidad de violentar) los distintos sistemas de solución de conflictos propios de las culturas que lo conforman afianzando de este modo la diversidad de nuestro Estado, a fin de hacer posible el desarrollo en todos sus aspectos: económico, social, jurídico, cultural, etc.

En consecuencia pues, una teoría del derecho consuetudinario que atienda al fenómeno social étnico y que permita comprenderlo, debe ser considerada como una concepción completa de Derecho. Ello permitiría calificar a los sistemas jurídicos de los pueblos indígenas como todo un Sistema de Derecho, pleno y cabal, perteneciente a su vez al sistema global. Por ello, una propuesta de derecho consuetudinario es también una propuesta de teoría de derecho nacional. 


\section{Conclusiones}

1. Conceptos tales como jurisdicción, función jurisdiccional y tutela jurisdiccional permiten definir claramente las funciones y obligaciones ineludibles del Estado. De tal forma que se entiende que los Estados están obligados a brindar un servicio de justicia que permite a los sujetos que lo conforman el arreglo de sus diferencias.

2. En función del cumplimiento de la obligación del Estado de brindar justicia, el ordenamiento jurídico, permite la existencia (coexistencia) de otros sistemas de heterocomposición, allí donde el Estado no llega. Estos sistemas no implican una excepción a la jurisdicción, sino por el contrario permiten al propio Estado cumplir con su deber de otorgar tutela jurisdiccional efectiva o simplemente tutela jurídica.

3. El reconocimiento de los sistemas permite cumplir al Estado un deber impuesto: la tutela jurisdiccional efectiva, la cual se hace posible con la delegación facultades para juzgar determinados asuntos a los propios grupos étnicos; es decir, se hace posible mediante la determinación de una competencia que, por la propia naturaleza de los grupos étnicos, es especial.

4. La evolución de los textos normativos, legales y constitucionales, nos muestra el interés del Estado en reconocer a los distintos grupos étnicos que lo conforman, siendo el reconocimiento más importante y de mayor trascendencia el de los sistemas de solución de conflictos propios a las Comunidades Étnicas.

5. En vista que los sistemas vigentes de solución de conflictos no se encuentran precisamente en oposición, cabe la labor de articularlos. La articulación de los sistemas evita el conflicto estructural al interior de un Estado, permite su afirmación en las sociedades y logra el progreso tan ansiado en las sociedades que así lo exigen. Es por ello, que en busca de una articulación de los sistemas conviene analizar los términos en que está expresado este Derecho diverso y especial en busca de mantener y lograr dentro de su diversidad la unidad.

6. Los miembros de los distintos grupos étnicos, ejercen un tipo de control social mediante la sanción entre sí y además cumplen una labor plenamente participativa de los lineamientos, políticos, sociales, económicos dentro de la organización comunal. Tienen un reconocimiento especial y distinto al de otros grupos sociales semiautónomos. 
7. Debemos lograr que el ordenamiento jurídico nacional reconozca sin violentar los distintos sistemas de solución de conflictos propios de las culturas que lo conforman. Debemos lograr que se afiance la diversidad de nuestro Estado, y que se articulen los sistemas a fin de hacer posible el desarrollo en todos sus aspectos: económico, social, jurídico, cultural, etc.

8. La regulación de los institutos en las Comunidades Nativas, mantiene similitudes y diferencias con el ordenamiento que prescribe nuestro código civil.

No obstante, podemos observar que las diferencias generan graves problemas de conflicto estructural, no en razón del sistema de solución de conflictos, sino del tratamiento propio del instituto. Para el caso del matrimonio Aguaruna, esencialmente es la unión de varón y mujer; sin embargo, el acto requiere aprobación de los padres y además deja abierta la posibilidad de una unión distinta a la concebida en el ordenamiento que prescribe nuestro código: la poligamia.

9. Los vacíos empíricos y la proyección de ellos, permite observar nuevas formas de solución no previstas por los propios institutos, tal como ocurrió en el caso del divorcio Asháninka, donde el instituto se origina según los patrones externos (matrimonio civil) pero se ejerce dentro de los patrones culturales internos de la comunidad, creando o recreando una forma no contemplada de solución imprevista por el ordenamiento jurídico global.

10. Demostrar una teoría del derecho consuetudinario que atienda al fenómeno social étnico y que permita comprenderlo, debe ser considerada como una concepción completa de Derecho. Permitirnos calificar a los sistemas jurídicos de los pueblos indígenas como todo un Sistema de Derecho, pleno y cabal, perteneciente a su vez al sistema global es una meta que genera progreso. Por ello, una propuesta de derecho consuetudinario es también una propuesta de teoría de derecho nacional. 


\section{Bibliografía}

Ballón Aguirre, Francisco.- Etnia y represión penal. Ital. Lima 1980.

La Amazonía en la norma oficial peruana: 1821 - 1990. Centro de Investigación y promoción Amazónica. Tomo I. Lima 1991.

Sistema jurídico Aguaruna y Positivismo. Centro de Investigación y promoción Amazónica. Lima

Benavides Matarazzo, Margarita. «Autodefensa Asháninka, organizaciones nativas y autonomía indígena». En: Perú: el problema agrario en debate. SEPIA. Lima 1992, pp. 539 - 560.

Centro de Investigación y Promoción Amazónica - CIPA. Derechos de las Comunidades Nativas y de sus Miembros. CIPA. Lima 1985.

Guallart Martínez, José María. El mundo mágico de los Aguarunas. Centro Amazónico de Antropología y Aplicación Práctica. Lima 1989.

Harrington Preston, Susan. Frente al cambio. Comunidades Nativas de la Amazonía peruana. Instituto Lingüístico de Verano. Lima 1992.

Hoyos Henrechson, Francisco. Temas Fundamentales de Derecho Procesal. Editorial jurídica de Chile. Santiago 1986.

Luna Pineda, Fabiola. "Participación de las Comunidades Nativas en el desarrollo nacional». En: Desarrollo y participación de las Comunidades Nativas. Centro Amazónico de Antropología y Aplicación Práctica. Lima, julio. 1997, pp. 19 - 28.

Monroy Gálvez, Juan. Introducción al proceso civil. Editorial Temis. Tomo I. Santa Fe de Bogotá 1996.

"Las excepciones en el código procesal civil peruano». En: Thémis. Lima. No 27 - 28. 1994.

Ochoa Siguas, Nancy. «Apuntes sobre la noción de justicia entre los Chayahuita». Primera versión de una investigación elaborada para el Cen- 
tro Amazónico de Antropología y Aplicación Práctiva - CAAAP. En: Comunidades Campesinas y Nativas en el nuevo contexto nacional. Centro Amazónico de Antropología y Aplicación Práctiva - CAAAP. Lima 1993, pp. $191-217$.

Sagüés, Néstor Pedro. «La jurisdicción militar en Argentina». En: Jurisdicción Militar y Constitución en Iberoamérica. Grijley. 1997.

Santistevan de Noriega, Jorge. «La Defensoría el Pueblo y las Comunidades Nativas». En: Desarrollo y participación de las Comunidades Nativas. Centro Amazónico de Antropología y Aplicación Práctica. Lima, julio 1997, pp. 29 - 35.

Varese, Stefano. "Las sociedades nativas de la selva peruana». En: Las Comunidades Nativas de la Selva. Centro de Estudios de Participación Popular. Lima, abril 1974, pp. 1 - 27.

«Notas sobre el autogobierno en las sociedades nativas de la Selva». En: Las Comunidades Nativas de la Selva. Centro de Estudios de Participación Popular. Lima, abril. 1974, pp. 86 - 92.

Yáñez Boluarte, Carlos. «Retos y posibilidades de los pueblos indígenas amazónicos ante el tercer milenio". En: Desarrollo y participación de las Comunidades Nativas. Centro Amazónico de Antropología y Aplicación Práctica. Lima, julio 1997, pp. 37 - 56. 